\title{
Permeability, porosity and surface characteristics of filter cakes from water-bentonite suspensions
}

\author{
V. C. Kelessidis, C. Tsamantaki, N. Pasadakis, E. Repouskou \\ \& E. Hamilaki \\ Department of Mineral Resources Engineering, \\ Technical University of Crete, Chania, Crete, Greece
}

\begin{abstract}
Water - bentonite suspensions behave as non-Newtonian fluids with exceptional rheological and filtration characteristics at low temperatures which deteriorate at temperatures higher than $120^{\circ} \mathrm{C}$. Additives restore these characteristics but many of them are thermally unstable at the temperatures encountered, for example in oil-well and geothermal drilling. Greek lignite has been proven to be an excellent additive for water-bentonite suspensions at temperatures up to $177^{\circ} \mathrm{C}$.

In this work we attempt to assess the reason for such good performance by studying the surface characteristics and the permeabilities of filter cakes of water - bentonite suspensions with and without the additive (various lignite types) after exposing the samples to thermal static aging at $177^{\circ} \mathrm{C}$ for 16 hours.

The filter cakes are produced with an American Petroleum Institute filter press allowing filtration for sufficient time to produce a filter cake with adequate thickness. The surface morphology of the filter cakes has been assessed with a scanning electron microscope. The permeabilities of the filter cakes were determined with an in-house technique which creates a 'wet core' of the filter cake of sufficient thickness and the water permeability is measured in a Hassler type meter. The differences between the reference samples (cakes from bentonite suspensions at room temperature) with cake samples from thermally aged water-bentonite suspensions and water-bentonite-lignite suspensions both in surface characteristics and in cake permeability are noted and discussed.
\end{abstract}

Keywords: filter-cake, permeability, lignite, bentonite, high-temperature. 


\section{Introduction}

The creation of low permeability filter cakes is one of the desirable properties of water-bentonite suspensions used as drilling fluids in order to minimize fluid loss into permeable formations which could be detrimental to hydrocarbon identification and production.

The filtration properties of bentonite-water suspensions are greatly affected by the way bentonite particles associate and the state of the suspension, being flocculated or deflocculated, aggregated or dispersed. The best filtration performance is when a clay suspension is deflocculated and dispersed since the very small clay particles give low porosities and permeabilities of the filter cake that is formed. When bentonite particles are flocculated, they are larger, giving higher porosities and permeabilities. Soluble salts in muds increase cake permeability but thinners usually restore these permeabilities because they disperse clay aggregates into smaller particles. Filter cake permeabilities are of the order of $10^{-2} \mathrm{mD}$ for flocculated suspensions, of the order of $10^{-3} \mathrm{mD}$ for untreated fresh water muds and of the order of $10^{-4} \mathrm{mD}$ for muds treated with thinners [1].

Fluid loss through such filter cakes is generally measured in the laboratory in a single pressure drop, usually 6.9 bar (100 psi), with an American Petroleum Institute standardized procedure $[2,3]$. In reality, however, the filter cakes are exposed to different differential pressures and different drilling fluid formulations requiring thus a general understanding of the properties of filter cakes [4] which will help predict not only fluid loss in conditions different from the lab but also the behavior under extreme conditions like high temperatures which are encountered now more often in oil-well exploration.

Filter cakes of bentonite-water suspensions are low in permeability, compressible and compactable [5]. To obtain the permeability of the filter cake, $k$, a permeating fluid of known pressure gradient should be applied to the sample and the permeable flux should be measured. If the applied pressure is large in order to give a measurable flux, the sample may deform. In addition, sealing of the boundaries of a wet and deformable sample may be difficult. Thus, measuring the permeability of the filter cakes in a direct way over a large porosity range is very difficult. It is for this reason that specific values of the permeabilities of filter cakes are not usually reported in the literature. Indirect techniques for measuring cake permeability have been reported by Meeten and Sherwood [5] using an inversion technique, which requires data obtained from filtration measurements at a series of pressure gradient values.

The good properties of bentonite-water suspensions deteriorate at temperatures above about $120^{\circ} \mathrm{C}[1,6]$. When drilling stops, the drilling fluid may stay static for a long time while it is exposed to high temperatures and strong gels may develop which cause excessive pressure drop when flowing and do not form good filter cakes. Therefore, water-bentonite suspensions are treated with various materials, to enable them to withstand these high temperatures [7]. The stability of bentonite suspensions at high temperatures may be improved either by modifying the surface charge of bentonite particles or by introducing a 
steric barrier against agglomeration using various additives which may be either modified, or non-modified, natural products like lignosulfonate complexes with various metals, tannins, humic acid, lignite and modified lignite, synthetic polymer products, mono- or poly-acrylic acid $[8,9]$. Lignite has been used together with many other substances like sodium chromate as alkali solubilized lignite to improve filtration and thermal stability of chrome-lignosulfonate drilling fluids $[1,7,10]$.

Results have been reported $[11,12]$ which show that several Greek lignite types can be used as additives, at optimum concentration of $3 \%$ in water-bentonite suspensions giving exceptional filtration control properties even after the bentonite-lignite-water suspension has been exposed to $177{ }^{\circ} \mathrm{C}$ for 16 hrs. The performance has been equal or sometimes even better to suspensions with a commercial lignite additive. However, the mechanism of action of the lignite additives for improving the performance of water-bentonite suspensions at high temperatures has not been understood. It is the intention of this ongoing research work to attempt to understand some of the mechanisms involved and processes that take place in such systems. This is accomplished by examining the surface characteristics of filter cakes using scanning electron microscopy and by directly measuring filter cake permeabilities, of filter cakes created with different water-bentonite suspensions, using two different bentonites and various lignite types as additives. In the present work the methodology that was developed will be presented together with preliminary experimental results.

\section{Experimental procedure}

Two sodium bentonites were used, a Greek bentonite (Zenith, kindly provided by S \& B Industrial Minerals S.A.) and a Wyoming bentonite (kindly provided by Baroid - Cebo Holland). Various lignite types from different places in Greece, which were provided by the Greek Institute of Geological and Minerealogical Exploration [11] as well as a commercial lignite (Caustilig) kindly provided by M-I Drilling Fluids were used as additives. The particle size of both bentonites is finer than $70 \mu \mathrm{m}$, thus meeting the API 13A specifications [2], while lignite samples were ground, when needed, to less than $70 \mu \mathrm{m}$.

The suspension preparation procedure followed the specifications of the American Petroleum Institute for drilling fluids [2, 3]. The water-bentonite suspension constitutes of deionized water and bentonite clay in the proportion of $6.42 \mathrm{gr}$ of bentonite in $100 \mathrm{gr}$ of deionized water, while in case of additive addition the proportion is $3 \mathrm{gr}$ of lignite in $100 \mathrm{gr}$ of deionized water. After mixing, the suspensions were either stored in sealed containers for full hydration for about 16 hours at room temperature (hydrated samples) or placed in a high temperature aging cell, pressurized at $100 \mathrm{psig}$ to avoid the evaporation of water and statically aged at $177^{\circ} \mathrm{C}$ for 16 hours in a portable oven (thermally aged samples) [11]. The static aging procedure simulates the behaviour of the static muds in high temperature wells. The $\mathrm{pH}$ of the suspensions was 9.82 for Zenith and 9.00 for Wyoming bentonite. At $\mathrm{pH}$ range of 9.0 to 10.0 the rheological and filtration properties of water-bentonite suspensions are insensitive to changes in $\mathrm{pH}[13]$. 
After aging, the filtration properties of the suspensions were measured in a Low Pressure - Low Temperature (LPLT) filter press (Fann 30201). The Whatman filter paper used in the API filter press has a retention size of $2.7 \mu \mathrm{m}$, an area of $4560 \mathrm{~cm}^{2}$ and offers no hydraulic resistance to the flow of water which flowed 100 to 1000 times faster compared to case when there was drilling fluid in the filter press [14]. Moreover, different filter paper retention size has also no effect on the filtration properties.

The API filtration procedure allows for 30 min filtration time and the filtrate is measured over this period and reported as fluid loss per thirty minutes. The filter cake that is produced over this period is fairly thin with a thickness of one to three millimetres $[1,11]$. Investigation of surface morphology of the cake can be performed on a cake of such thickness as the material required is extremely small. However, for the permeability measurements, a cake of sufficient thickness is required for use on the permeability apparatus. This was created by allowing filtration in the filter press for about $16 \mathrm{hrs}$ and at that time only a very low volume of filtrate was flowing from the press. This procedure gave a fairly thick filter cake of approximately $10-15 \mathrm{~mm}$ thickness while at the same time it resulted in an almost uniform cake concentration allowing full compaction of the filter cake. Similar procedures have been followed by Meeten and Sherwood [4] and Sherwood et al. [15] who have confirmed experimentally the uniform cake thickness.

Drying of the filter cake for use in SEM was accomplished under room temperature conditions $\left(\sim 25^{\circ} \mathrm{C}\right)$, without placing the filter cake in an oven or other drying equipment. It was observed that few days were needed ( $\sim 3-4$ days) for the filter cake to become completely dry. The cake was then prepared for SEM observations. Analysis of morphology of filter cakes created by water-bentonite suspensions have been performed in particular for drilling fluid characterization by Porter [16], Hartmann et al. [17], Plank and Gossen [18] and Chenevert [19]. In this work the microstructure of the fillter cakes was studied by scanning electron microscope (SEM) JEOL JSM 5400, working at $15 \mathrm{kV}$ of electron accelerating voltage. The dried filter cakes were mounted and gold coated with a layer about $10 \mathrm{~nm}$ thick by using a vacuum of $10^{-3}$ Torr metalcoating process. Microchemical qualitative analyses of clay and lignite particles were carried out using an EDS energy dispersive X-ray analyzer INCA Energy 300. Each sample was studied at several magnifications. The $x 3500$ and $\times 7500$ magnifications were taken as optimal for study of the microstructure details and the results presented are at the $\mathrm{x} 7500$ magnification.

The permeability of the mud cake was measured using an in-house developed experimental setup based on a Hassler type core holder. The mud cake as it was produced from the API filter press was loaded in a ring with $2.54 \mathrm{~cm}$ external diameter, $0.1 \mathrm{~cm}$ thickness and $0.5 \mathrm{~cm}$ length. The ring was subsequently placed between two Berea core samples, $2.54 \mathrm{~cm}$ diameter and $2 \mathrm{~cm}$ long each, of known permeability. The specimen, consisting of the two cores and the ring containing the mud cake was encased in a thermo-shrinkage plastic (Figure 1) and placed in the sample holder of a Hasser type core holder. Water was injected in the sample using an Isco positive displacement pump at a constant pressure of 
105 psi. After equilibration, the flow though the core was measured and the permeability of the filter cake was determined assuming flow though porous media in series.

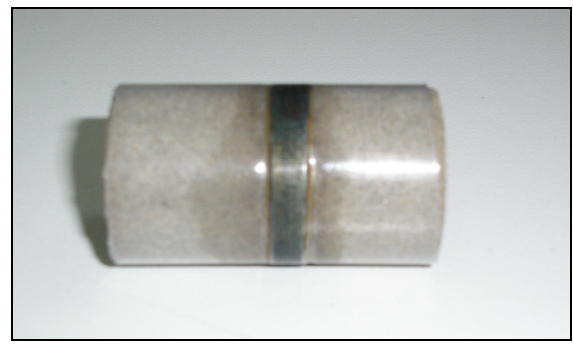

Figure 1: In-house developed specimen used for permeability experiments.

\section{Experimental results}

SEM and permeability results are presented for filter cakes created using two bentonites and two lignites, a commercial product $(\Gamma)$ and a Greek lignite (TH7).

In Figure 2 the SEM pictures of the tested filter cakes are shown. All the pictures were taken in a plane perpendicular to the flow plane of the filter cakes. Evident differences in the character of the formed microstructure of the different filter cakes can be observed. The microstructure of the hydrated Wyoming filter cakes (Fig. 2(a)) are characterized by large amounts of leafs placed very closely to each other and thus creating compact orientated layers of smectite particles (EDS analysis). The hydrated Zenith filter cakes (Fig. 2(b)) create very similar microstructure to the Wyoming ones, with comparable particle sizes, densities and compactness of individual grains. The filter cakes from the thermally aged Wyoming and Zenith suspensions (Fig. 2(c), 2(d)) present a more permeable microstructure, which is characterized by a large amount of leafs with open-air voids having small interfacial zones and mutual bonds. The SEM micrographs of the filter cakes treated with commercial lignite $\Gamma$ (Fig. 2(e) and 2(f)) and with Greek lignite TH7 (Fig. 2(g) and 2(h)) show that the cakes have undergone a reduction in porosity compared to the corresponding thermally aged ones. The smectite particles draw closer and their interaction increases, so they give a less permeable microstructure.

In Figure 3 the measured permeabilities of the tested filter cakes are shown. The results reveal first of all that on the two identical tests that have been performed with Wyoming-bentonite filter cakes, the measured permeabilities are within $5 \%$ of each other, indicating the measurement capabilities and the repeatability of the system set-up. Secondly, the values of the permeabilities of all samples are very small, of the order between $10^{-4}$ and $10^{-3} \mathrm{mD}$, close to the permeability values of filter cakes observed from fresh-water muds and muds treated with thinners [1]. Evaluation of the Wyoming-bentonite results shows the significant reduction in permeability values on the samples treated with 
178 Computational Methods in Multiphase Flow IV
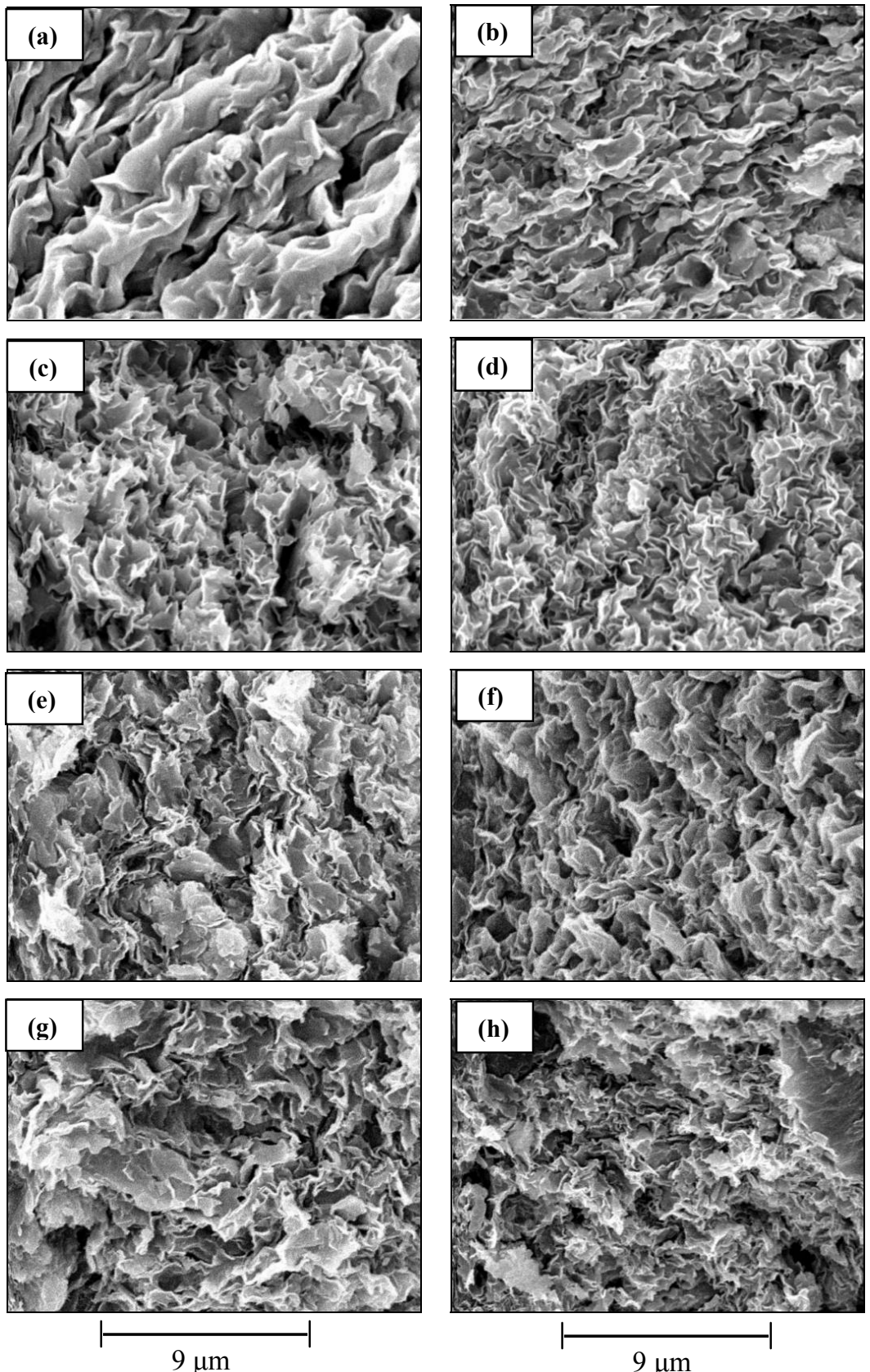

Figure 2: Scanning electron micrographs (SEM) of tested filter cakes. Magnification x7500: (a) H-W, (b) H-Z, (c) TA-W, (d) TA-Z, (e) $\mathrm{TA}-\mathrm{W}+\Gamma$, (f) $\mathrm{TA}-\mathrm{Z}+\Gamma$, (g) TA-W+TH7, (h) TA-Z+TH7 (H: hydrated, TA: thermally aged, W: Wyoming, Z: Zenith).

WIT Transactions on Engineering Sciences, Vol 56, (c) 2007 WIT Press

www.witpress.com, ISSN 1743-3533 (on-line) 


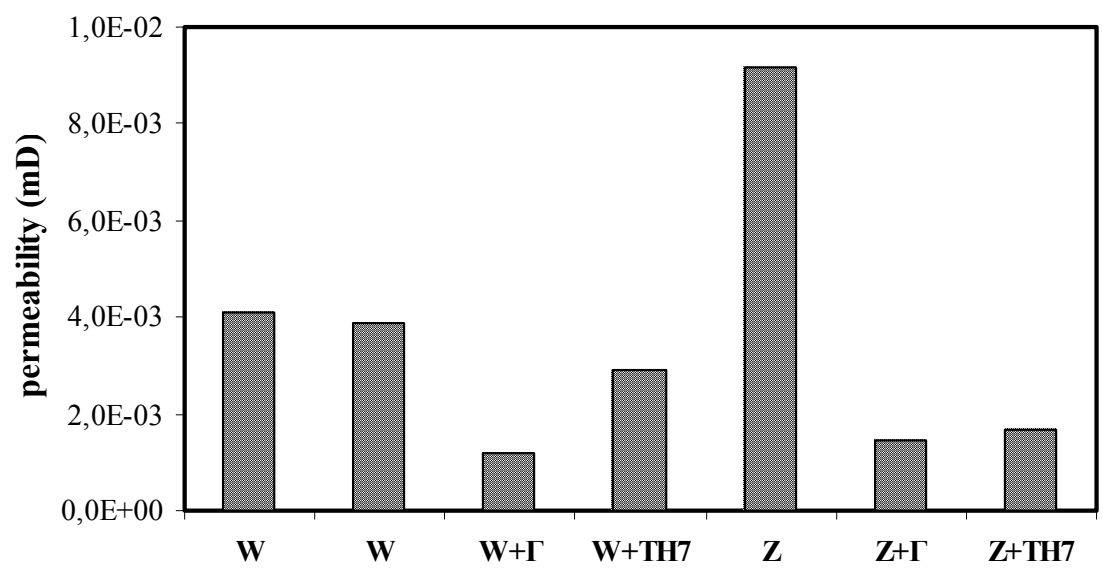

Figure 3: Measured permeabilities of filter cakes of the tested bentonitewater suspensions. All suspensions have been thermally aged.

lignite. The effect of the different lignite types is different, with the commercial lignite $(\mathrm{W}+\Gamma)$ giving a permeability ratio to the permeability with only bentonite of 4.1/1.21=3.4, better than the TH7 lignite, which gives a ratio of 4.1/2.89=1.4. Evaluation of the Zenith bentonite suspension results shows the higher permeability values of the filter cake of the Zenith suspension, compared to the Wyoming counterpart, with a ratio of the two permeabilities of 9.17/4.1=2.2. Lignite addition lowers again the permeability of the filter cakes, with the different lignites having different effect. Better performance is observed with the commercial lignite $(Z+\Gamma)$ with a ratio of permeabilities of $9.17 / 1.45=6.3$, while lignite TH7 exhibits a very good performance as well, giving a ratio of 9.17/1.69=5.4. Furthermore, the values of the permeability of the filter cakes obtained with the Zenith-suspensions and with the two lignite types are comparable to the Wyoming counterparts.

\section{Discussion}

Based on the analysis of the SEM micrographs of the filter cakes created with water-bentonite suspensions, it appears that the structure of the filter cake changes according to the additive in the suspension and to the treatment it has undergone. When no additive is present and the suspensions has been only hydrated for $16 \mathrm{hrs}$, the bentonite platelets, Zenith or Wyoming, are aligned in a direction almost normal to the flow direction, creating a network structure that results in a very low permeability of the filter cake, thus giving low fluid loss value and hence making the suspension excellent for use in drilling applications. When the same suspensions are thermally aged to $177^{\circ} \mathrm{C}$, the filter cakes created afterwards offer a more permeable structure, which results both from the association of several clay platelets and the opening up of the platelets thus 
leaving more open space. This is observed for both bentonite types. The addition of the two lignites studied, $\Gamma$ and TH7, presents a different filter cake structure from the previous two. The micrographs show that the clay platelets are smoothly associated, although not in the same way as when the bentonite is only hydrated, thus leaving probably similar open space to the hydration case resulting in similar permeability values among each other and with the hydrated case and much smaller than the case when the suspension is thermally aged. No identifiable differences can be reported from these SEM micrographs from the filter cakes derived with the different lignite types.

The permeability measurements are similar to the SEM micrograph observations and show the decrease in permeability values for the filter cakes derived with the suspensions treated with lignite. However, the permeability measurements indicate differences also among the lignite types. However, it should be noticed that the values of the permeability of the filter cakes are extremely small when compared, for example with permeabilities of the permeable formations, which are of the order of 0.1 to $1000 \mathrm{mD}$. Thus, the developed technique allows for the identification of differences among the lignite types, but one should look at the essential differences which are the ones between bentonite suspensions and bentonite-lignite suspensions.

\section{Conclusions}

A methodology has been established for the evaluation of the permeability and the surface characteristics of filter cakes created by using different water-bentonite suspensions. The methodology involves the creation of adequate thickness filter cake in an API filter press, the evaluation of surface morphology of the filter cake by scanning electron microscopy and the measurement of the permeability of the filter cake.

The permeability measurement presented significant challenges which have been resolved. The thick filter cake is placed between two cores of known permeability and thickness, all held together in a thermo-shrinkage plastic and put in a Hassler type holder for the permeability measurement with water. The technique has been tested and gives repeatable results. It should be stressed that permeability measurements of filter cakes rarely appear in the literature.

The technique has been applied to study the characteristics of filter cakes from Wyoming and Zenith bentonite-water suspensions at $6.42 \%$ wt. which were hydrated, thermally aged and thermally aged after adding different lignites at 3\% wt.

SEM micrographs reveal that hydrated bentonite suspension filter cakes form a network of platelets almost normal to the flow direction. This structure opens up when the suspension is thermally aged and multiparticle association is observed increasing the permeability of the filter cake. The addition of the two lignite types studied gives a structure which is closed again and not leaving much open space for the flow of the filtrate. There were not many differences observed among the filter cakes of the two different lignites that were analyzed with SEM. 
The permeability measurements give permeability values for the thermally aged suspensions for both bentonites used which are typical of flocculated suspensions, with a variation among the two bentonite types. Additions of lignite at 3\% wt. results in drastic reduction of the permeability of filter cakes derived after thermal aging of the suspension. Variations in permeability values have been observed between the different lignites tested.

\section{Acknowledgements}

This work has been funded by the Greek State, under the contract Pythagoras II, Technical University of Crete - Project 8. The provision of Greek lignites by IGME, Greece, of Zenith bentonite by $\mathrm{S} \& \mathrm{~B}$ Industrial Minerals S.A., of Wyoming bentonite by Baroid-Cebo Holland and of Caustilig by M-I Drilling Fluids are greatly appreciated.

\section{References}

[1] Gray, H. C. H. and Darley, G. R., Composition and properties of oil well drilling fluids, Gulf Publishing Co., $6^{\text {th }}$ Edition, Houston, USA, 1980.

[2] American Petroleum Institute Specifications 13A, Specification for drilling fluid materials, 1993.

[3] American Petroleum Institute Specifications 13I, Recommended practice standard procedure for laboratory testing drilling fluids, 2000.

[4] Sherwood, J. D. \& Meeten, G. H., The filtration properties of compressible filter cakes. Journal of Petroleum Science and Engineering, 18, pp. 73-81, 1997.

[5] Meeten, G. H. and Sherwood, J. D., The hydraulic permeability of bentonite suspensions with granular inclusions. Chemical Engineering Science, 49(19), pp. 3249-3256, 1994.

[6] Bleler, R., Selecting a drilling fluid. J. Petr. Techn., 42(7), pp. 832 - 834, 1990.

[7] Clark, R. K., Impact of environmental regulations on drilling fluid technology. J. Pet. Techn., 46(9), pp. 804 - 809, 1994.

[8] Rabaioli, M.R., Miano, F., Lockhart, T. P., and Burrafato, G., Physical/chemical studies on the surface interactions of bentonite with polymeric dispersing agents, SPE 25179. Intern. Symposium on Oilfield Chemistry, New Orleans, LA, U.S.A, 1993.

[9] Burrafato, G., Miano, F., Carminati, S. and Lockhart, T. P., New chemistry for chromium free bentonite drilling fluids stable at high temperatures, SPE 28962. SPE Intern. Symposium on Oilfield Chemistry, San Antonio, TX, USA, 1995.

[10] Nyland, T., Azar, J. J., Becker, T. E. and Lummus, J. L., Additive Effectiveness and Contaminant Influence Control on Fluid Loss control of Water-Based Muds. SPE Drill. Engr., 6, pp. 195-203, 1988.

[11] Mihalakis, A., Makri, P., Kelessidis, V.C., Christidis, G., Foscolos, A. and Papanikolaou, K., Improving Rheological And Filtration Properties of 
Drilling Muds with Addition of Greek Lignite. Proceedings of the 7th National Congress on Mechanics, edited by A. Kounadis, K. Providakis and G. Exadaktylos, Chania, Greece, pp. 393-398, 2004.

[12] Kelessidis, V. C., Mihalakis, A., Tsamantaki, C., Rheology and rheological parameter determination of bentonite-water and bentonitelignite-water mixtures at low and high temperatures. Proceedings of the 7th World Congress of Chem. Engr., Glasgow, 2005.

[13] Alderman, N., Ram Babu, D., Hughes, T. \& Maitland, G., The rheological properties of water-based drilling fluids - effect of bentonite chemistry, Speciality Chemicals, Production, Marketing and Applications, 9 (5), pp. 314-326, 1989.

[14] Meeten, G. H., Shear and compressive yield in the filtration of a bentonite suspension. Colloids and Surfaces A: Physicochemical and Engineering Aspects, 82, pp. 77-83, 1994.

[15] Sherwood, J. D., Meeten, G. H., Farrow, C. A., Alderman, N. J., The concentration profile within non-uniform mud cakes. J. Chem. Soc. Faraday Trans., 87(4), pp. 611-618, 1991.

[16] Porter, K. E., A basic scanning electron microscope study of drilling fluids, paper SPE 8790. Presented at the 4th Symposium on Formation Damage Control, Bakersfield, CA, 1980.

[17] Hartmann, A., Ozerler, M., Marx, C. and Neuman, H-J., Analysis of mudcake structures formed under simulated borehole conditions. SPE Drill. Engr., pp. 395-402, 1988.

[18] Plank, J. P. and Gossen, F. A., Visualization of fluid-loss polymers in drilling mud filter cakes. SPE Drill. Engr., pp. 203-208, 1991.

[19] Chenevert, M. E., Filter cake structure analysis using the scanning electron microscope, paper SPE 22208, unsolicited. Society of Petroleum Engineers, Richardson, TX, 1991. 